\title{
ANÁLISE BIBLIOMÉTRICA SOBRE CAPITAL SOCIAL E GOVERNANÇA LOCAL NO CONTEXTO DOS ARRANJOS PRODUTIVOS LOCAIS

\author{
Valdir Serafim Junior ${ }^{1}$ \\ Fabíola Graciele Besen ${ }^{2}$ \\ Sandra Maria Coltre ${ }^{3}$
}

\begin{abstract}
Resumo
O estudo analisou a produção científica sobre Capital Social e Governança Local no contexto dos Arranjos Produtivos Locais. A pesquisa foi exploratória e bibliométrica (documental), de cunho quantitativo, pois os dados foram oriundos de apenas de fontes secundárias. O levantamento das publicações foi realizado no Portal de Periódicos da Coordenação de Aperfeiçoamento de Pessoal de Nível Superior (CAPES), Scientific Periodicals Electronic Library (SPELL) e Scientific Electronic Library Online (SCIELO). Os resultados evidenciam que os anos de 2013 e 2017 foram os de maior número de publicações, com maior número de artigos concentrados em revistas B1 e B2. Os APLs mais estudados foram no setor têxtil e confecções, seguidos de software e tecnologia, com estudos mais concentrados na Região Sul, Sudeste e Nordeste, poucos estudos na região Norte e nenhum estudo na região Centro-Oeste. E, que pesquisas sobre Capital Social em seus variados vieses, necessitam ser ampliadas.
\end{abstract}

Palavras-chave: Arranjos produtivos locais. Capital Social. Governança. Bibliometria.

1 Bacharel em Ciências Contábeis. Mestre em Extensão Inovadora e Desenvolvimento Rural Sustentável. Atualmente, cursa doutorado em Desenvolvimento Rural Sustentável pela Universidade Estadual do Oeste do Paraná (Unioeste). Professor do Curso de Ciências Contábeis da Unioeste - Campus de Foz do Iguaçu. E-mail: jr_valdir@hotmail.com

2 Bacharel em Ciências Contábeis. Mestre em Extensão Inovadora e Desenvolvimento Rural Sustentável. Atualmente, cursa doutorado em Desenvolvimento Rural Sustentável pela Universidade Estadual do Oeste do Paraná (Unioeste). Professora do Curso de Ciências Contábeis da Unioeste - Campus de Foz do Iguaçu. E-mail: fabiolagracielebesen@gmail.com

3 Bacharel em Administração. Mestre em Engenharia da produção. Doutora em Engenharia da Produção pela Universidade Federal de Santa Catarina (UFSC). Professora do Curso de Administração da Universidade Estadual do Oeste do Paraná (Unioeste) Campus de Foz do Iguaçu. E-mail: sandracutu@gmail.com 


\section{Introdução}

Diversos estudos publicados nos últimos anos têm tratado sobre a temática do Arranjo Produtivo Local (APL) e sua importância para o desenvolvimento das organizações, buscando obter ganhos de competitividade (CASSIOLATO; LASTRES, 2003; MARINI, et al., 2012; COSTA et al., 2018, dentre outros).

A partir da década de 1990, iniciou-se uma preocupação para entender porque o nível de crescimento variava entre as regiões e nações, apesar de algumas disporem das mesmas condições na busca de fatores produtivos como capital financeiro, mão de obra e tecnologia. Passaram a surgir estudos para identificar, entre esses fatores, aqueles determinantes para que as organizações obtivessem vantagens competitivas em determinada região (PASSADOR, 2003).

Porter (1998) foi o autor que primeiramente chamou a atenção para os clusters de vinho na Califórnia (Estados Unidos) e de artigos de moda de couro na Itália; assim, os Arranjos Produtivos Locais (APL) vêm surgindo como solução interessante para alavancar resultados de pequenas e médias empresas (SOUZA et al., 2015).

Essa pesquisa está voltada aos Arranjos Produtivos Locais e ao Capital Social e à Governança Local dentro desses APLs, buscando as contribuições que os estudos presentes na literatura brasileira apresentam sobre esses temas, já que algumas das características que ajudam a consolidar um APL, como a Governança Local e o Capital Social, correspondem a principais formas que conduzirão o APL para o sucesso.

O termo Arranjo Produtivo Local surge no final dos anos 1990. E, segundo Suzigan (2006), é um conjunto de agentes políticos, econômicos e sociais de um mesmo setor produtivo e institucional, de forma que agregue benefícios com a aglomeração dessas empresas. Cassiolato e Lastres (2003) definem APL como um grupo de agentes econômicos, sociais e políticos com foco em um conjunto de atividades econômicas mais específico.

No Brasil, o poder público passou a se interessar por esse modelo com o lançamento do Programa Nacional de Apoio aos Arranjos Produtivos Locais (APLs) e a formalização de um Grupo de Trabalho Permanente (GTPAPL), que tem como objetivo integrar ações de órgãos e agências não governamentais, governamentais (nas diversas esferas: federal, estadual e municipal) e outras agências para sua promoção (NORONHA; TURCHI, 2005).

Diversas podem ser as caracterizações dos Arranjos Produtivos Locais e dependem de sua história, evolução, organização institucional, contexto social e cultural dentro da estrutura produtiva, além das formas de governança, o associativismo, a cooperação entre agentes, as formas 
de aprendizado e a capacidade de geração e a difusão de conhecimentos (VILPOUX; OLIVEIRA, 2010).

Porter (1990) destaca que a concentração geográfica das empresas de um ramo de atividade traz vantagens competitivas não só para as empresas, mas também para a comunidade e a sociedade na região em que estas se localizam (ZACCARELLI et al., 2008). Assim, torna-se importante avaliar a Governança Local e o Capital Social no contexto dos APLs.

A governança tem como objetivo estabelecer mecanismos de intervenção, comando, participação e aglutinar e estimular os resultados positivos coletivos dos participantes (CASSIOLATO; LASTRES, 2003). Começa a ocorrer uma interação entre os atores participantes na busca de objetivos comuns, melhorando as relações comerciais, aumentando a representatividade, legitimidade do grupo, credibilidade e força de mercado do grupo (VERSCHOORE; BALESTRIN, 2008). A importância da governança foi discutida em vários estudos. Para Storper e Harrison (1991), identificar a governança em um APL permite conhecer os atores, e estes podem definir os rumos do desenvolvimento desse APL. Segundo Schmitz e Knorringa (2000), identificar o tipo de Governança Local dá condições para avaliar o potencial das ações conjuntas no APL, ou no seu grau de institucionalização (GUSSONI, WEISE; MEDEIROS, 2015).

Em relação ao Capital Social, Putnam (2000, p. 117) o apresenta como: “[...] características da organização social, como confiança, normas e sistemas, que contribuem para aumentar a eficiência da sociedade, facilitando as ações coordenadas". Dessa forma, quando o Capital Social existe em alto grau é fato de grande importância para o bom andamento de um APL, visto que significa que os atores envolvidos desfrutam de interesse comum que é o fortalecimento do arranjo, trará maiores oportunidades para todos (FLORES; MARINI, 2018).

Esse estudo se justifica, pois, a junção entre Capital Social e Governança Local fortalece o APL, já que boas práticas de Governança Local agregam Capital Social ao APL; e, no sentido oposto, o Capital Social é capaz de conduzir o arranjo para uma Governança Local mais eficaz.

Além disso, torna-se importante pesquisar sobre Capital Social e Governança Local no contexto dos Arranjos Produtivos Locais. Uma das formas para conhecer o estado da arte é através da pesquisa bibliométrica, esta que, segundo Araújo (2006), é uma técnica quantitativa e estatística de medição da produção científica. Portanto, o estudo buscou responder à seguinte questão: Qual o perfil da produção científica sobre Capital Social e Governança Local no contexto dos Arranjos Produtivos Locais?

$\mathrm{O}$ estudo está dividido em cinco partes. A primeira versa sobre introdução, contextualização, objetivo e justificativa de estudo. $\mathrm{Na}$ segunda seção, tem-se a explanação dos conceitos ligados ao artigo, tais 
como: Arranjos Produtivos Locais, Governança Local e Capital Social. $\mathrm{Na}$ sequência, apresenta-se o caminho metodológico que orientou o estudo. Por fim, há a análise e a discussão dos resultados bem como as considerações finais.

\section{Revisão teórica}

A revisão teórica compreende a apresentação dos principais conceitos que norteiam o objetivo deste artigo. $\mathrm{O}$ primeiro item trata da sobre Arranjos Produtivos Locais, em seguida Capital Social e Governança Local.

Arranjos Produtivos Locais (APLs)

Emborahajaumaforteexpansãodocomérciointernacionaldaeconomia globalizada, os estudos têm voltado o olhar para o mercado consumidor local, pois a maior parte da produção ainda se destina a esse mercado. Dessa forma, há uma vertente que defende ser necessário analisar os determinantes da localização da produção no espaço, com ênfase na produção do sistema de cidades e nos novos modelos de produção, cada vez mais assentados nos processos de produção cooperativos, sem perder a dimensão competitiva (SANTOS, 2003).

Conforme Ferreira, Meireles, Macedo, Barrone, Sant'Anna e Zotes (2011, p. 522) "APL é caracterizado pela existência da aglomeração de um número significativo de empresas que atuam em torno de uma atividade produtiva principal".

Segundo Cassiolato e Lastres (2003), o foco em APLs permite a resolução de problemas que a abordagem tradicional não consegue, pois esta não considera a esfera local. Já essa nova abordagem leva em consideração as especificidades locais das diferentes atividades. Há a necessidade de considerar a dinâmica do território em que esses APLs se encontram, tendo em vista o número de postos de trabalho, faturamento, diversificação, potencial de faturamento, mercado, entre outros (FERREIRA; MEIRELES; MACEDO, 2011).

Lopes e Baldi (2005) afirmam que os Arranjos Produtivos Locais se formam em quatro etapas. 
Figura 1 - Etapas de formação dos Arranjos Produtivos Locais

\section{CONFIANÇA E COOPERAÇÃO}

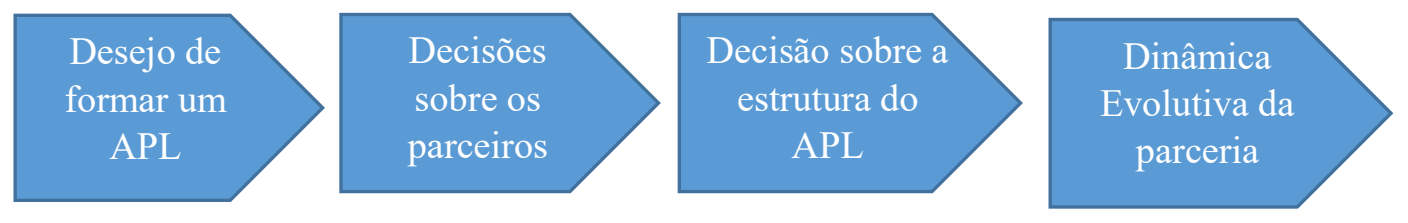

Fonte: Adaptada de Gulati (1995); Lopes e Baldi (2005).

Essas etapas não precisam obedecer necessariamente a essa mesma ordem. Mas de todas as variáveis envolvidas na formação, atuação e evolução dos APLs, a confiança e a cooperação são as que mais se destacam (LOPES; BALDI, 2005).

Em resumo, os APLs possuem, como proposta, possibilitar maiores vantagens competitivas, através de ações voltadas para a interação e cooperação entre os atores participantes, visando ao desenvolvimento local e regional, por meio de apoio do Estado, associações, além de desenvolvimento tecnológico e formação profissional (CASSIOLATO; LASTRES, 2003).

Para Suzigan, Garcia e Furtado (2002, p. 3), os APLs são moldados a partir de uma trajetória histórica que "[...] molda fatores endógenos locais como a especialização produtiva, as lideranças, a confiança entre os agentes, a criação de instituições de apoio, a estrutura de governança e o equilíbrio entre cooperação e competição". Portanto, estes arranjos podem possibilitar o aumento de Capital Social em prol de sua sustentabilidade.

\section{Capital Social}

O Capital Social é um conceito diferente do capital humano e de infraestrutura; por essa razão, não se pode confundi-los. O capital humano se refere às habilidades e aos conhecimentos dos indivíduos que, unido a outras características pessoais e o esforço despendido, aumenta as possibilidades de produção e de bem-estar pessoal, social e econômico. Parte desse capital ocorre em um processo de aprendizagem, mas tanto a sua aquisição quanto o seu uso são processos afetos ao indivíduo. A infraestrutura, por sua vez, refere-se ao conjunto fundamental de instalações e meios para que a produção se realize e se distribua (MARTELETO; SILVA, 2004).

$\mathrm{Na}$ maior parte dos estudos sobre o Capital Social, destacam-se três teóricos: Pierre Bourdieu (1985), James Coleman $(1988,1990)$ e Robert Putnam (1996).

Bourdieu (1985) define Capital Social como a soma de recursos efetivos unidos por uma rede durável de relações de conhecimento ou 
reconhecimento jurídico mútuo. Segundo esse autor, o Capital Social pode ser alavancado a partir das atitudes e dos pensamentos do grupo da comunidade; conforme aumenta esse grau de pertencimento do cidadão com a comunidade, aumenta-se o Capital Social (BOURDIEU, 1985).

Coleman (1988, p. 32) assim se refere acerca de Capital Social: "[...] as ações das pessoas são moldadas, redirecionadas, constrangidas pelo contexto social; normas, confiança interpessoal, redes sociais, e a organização social são importantes para o funcionamento não só da sociedade, mas também da economia”.

Para Putnam (2000,p. 117), a característica central do Capital Social é que se trata de um bem público e descreve este como "[...] características da organização social, como confiança, normas e sistemas, que contribuem para aumentar a eficiência da sociedade, facilitando as ações coordenadas”. Ainda, conforme esse autor, para a estabilidade política, para a boa governança e mesmo para o desenvolvimento econômico, o Capital Social pode ser mais importante até do que o capital físico e humano; então, criar Capital Social não é fácil, mas é essencial para fazer a democracia funcionar (PUTNAM, 2000).

Marini et al. (2012) destaca que um APL apresenta características bem distintas, dentre elas o Capital Social, proveniente da relação entre seus agentes (empresas, instituições de ensino, instituições de fomento, agentes públicos, organizações) que colaboram para o aperfeiçoamento e desenvolvimento de uma atividade específica. E, quando ocorre cooperação, engajamento e confiança, características do Capital Social, o APL se fortalece e se desenvolve pelo exercício de sua governança.

\section{Governança Local}

Para que ocorra o desenvolvimento dos Arranjos Produtivos Locais (APLs), Cassiolato e Lastres (2003) indicam que a forma como é feita a inter-relação entre os atores públicos e privados do arranjo é essencial. Por essa razão, a importância do que se denomina governança. Para os autores, a governança pode ser entendida como os meios pelos quais as pessoas, instituições e empresas administram seus problemas, resolvem seus conflitos e cooperam recorrendo a sistemas formais ou informais de coordenação (Cassiolato; Lastres, 2003).

Tem como objetivo estabelecer mecanismos de intervenção, comando, participação e aglutinar e estimular os resultados positivos coletivos dos participantes (BITANTE et al., 2018). Para que o APL cresça e se desenvolva, é necessária a adequação dos seus mecanismos de governança e de suas práticas de gestão, já que existem participantes internos e externos no arranjo, assim como também mais transações de negócio, sem deixar de estimular o caráter de cooperação dele (WEGNER; PADULA, 2010). 
A governança deve buscar para o desenvolvimento e sucesso dos arranjos produtivos ações que se concentrem nos processos de aprendizado coletivo, direcionamento comercial e tecnológico, resultados obtidos para criar condições favoráveis ao desenvolvimento de polos tecnológicos, além de estimular formas de cooperação entre instituições e empresas (LÖFFLER, 2001 apud BITANTE et al., 2018).

Santos (1997) já apontava que os atores participantes dos APLs buscavam sucesso profissional por meio de uma governança inteligente, eficaz e eficiente, e isso ainda é válido, como demonstram os estudos atuais pelos autores supracitados.

\section{Procedimentos metodológicos}

Este estudo é exploratório e bibliométrico em busca das tendências da temática pesquisada; dessa forma, segundo Beuren (2006), objetiva investigar de forma aprofundada sobre um assunto.

Os dados foram coletados, apenas, de fontes secundárias e artigos sobre o tema; por isso, o cunho do trabalho é quantitativo. A coleta ocorreu por meio de levantamento de artigos nacionais disponibilizados no Portal de Periódicos da Capes, SCIELO e SPELL por palavras-chaves: Arranjos produtivos locais e Capital Social*, Arranjos produtivos locais e Governança Local*. O asterisco é utilizado na busca do Portal da Capes para considerar as variações das palavras. $\mathrm{O}$ mesmo número de palavras-chaves foi utilizado em SCIELO e SPELL para a busca dos artigos. Não foi definido um período inicial e final; e, depois de efetuada a coleta, identificaram-se artigos dentro do período de 2004 a 2018.

De posse dos 397 artigos localizados através da busca, foi utilizado o software EndNotebasic (gerenciador bibliográfico), versão web (online) para organizar e evidenciar as principais características consideradas no estudo. De 397 artigos encontrados, 266 estavam vinculados às palavras chaves: Arranjos Produtivos Locais, Capital Social, Governança Local e suas variações.

$\mathrm{Na}$ sequência, efetuou-se a leitura do título e do resumo para identificar as pesquisas relacionadas com o objetivo deste estudo, resultando em 87 artigos. Por fim, foi feita a leitura criteriosa dos artigos, formando, assim, o portfólio final com 35 artigos, 20 artigos relacionados a Arranjos Produtivos Locais e Governança Local e 15 artigos relacionados a Arranjos Produtivos Locais e Capital Social. 
Quadro 1 - Etapas de formação do Portfólio*

\begin{tabular}{|l|l|}
\hline $\begin{array}{l}\text { 1\% Busca (Palavras-chave) } \\
\text { Capital Social - Governança Local - Arranjos Produtivos Locais: } 397 \text { artigos }\end{array}$ & $\begin{array}{l}\text { Portal Capes: } 275 \text { artigos } \\
\text { Portal Sciello: } 75 \text { artigos } \\
\text { Portal Spell: } 47 \text { artigos }\end{array}$ \\
\hline $\begin{array}{l}\text { 2o Busca (artigos vinculados às palavras chaves: "Arranjos Produtivos Locais e Capital } \\
\text { Social” “Arranjos Produtivos Locais e Governança Local” e suas variaçôes): } 266 \text { artigos } \\
\text { Capital Social e Arranjos Produtivos Locais: } 143 \text { artigos } \\
\text { Governança Local e Arranjos Produtivos Locais: } 123 \text { artigos }\end{array}$ & $\begin{array}{l}\text { Portal Capes: } 239 \text { artigos } \\
\text { Portal Sciello: } 15 \text { artigos } \\
\text { Portal Spell: } 12 \text { artigos }\end{array}$ \\
\hline $\begin{array}{l}\text { 3o Busca (Leitura dos títulos e resumos): } 87 \text { artigos } \\
\text { Capital Social e Arranjos Produtivos Locais: } 47 \text { artigos } \\
\text { Governança Local e Arranjos Produtivos Locais: } 40 \text { artigos }\end{array}$ & $\begin{array}{l}\text { Portal Capes: } 77 \text { artigos } \\
\text { Portal Sciello: } 3 \text { artigos } \\
\text { Portal Spell: } 7 \text { artigos }\end{array}$ \\
\hline $\begin{array}{l}\text { 4o Busca (Leitura criteriosa dos artigos): } 35 \text { artigos } \\
\text { Capital Social e Arranjos Produtivos Locais: } 15 \text { artigos } \\
\text { Governança Local e Arranjos Produtivos Locais: } 20 \text { artigos }\end{array}$ & $\begin{array}{l}\text { Portal Capes: } 25 \text { artigos } \\
\text { Portal Sciello: } 3 \text { artigos } \\
\text { Portal Spell: } 7 \text { artigos }\end{array}$ \\
\hline
\end{tabular}

* Dados da pesquisa.

Fonte: Elaborada pelos autores (2019).

No tratamento foram definidas e tabuladas as características dos artigos do portfólio, em software estatístico específico. Essas características são as variáveis consideradas para o estudo, sendo: periódicos com maior número de publicações, ano e quantidade de autores, palavras-chave mais citadas, qualificação da Revista no Qualis 2016, instituições envolvidas, APLs, regiões mais estudadas e redes de autores. A classificação Qualis 2016 dos respectivos periódicos se deu através do site da plataforma Sucupira e a quantidade de citações dos respectivos estudos foi identificada por meio do Google Scholar. É importante relatar que nem todos os artigos forneciam as informações investigadas.

\section{Análise dos dados}

Os resultados apresentados a seguir se referem ao portfólio final com 35 artigos, 20 artigos relacionados a Arranjos Produtivos Locais e Governança Local e 15 artigos relacionados a Capital Social e à Governança Local. Os resultados encontrados na pesquisa são apresentados para cada objetivo específico: periódicos com maior número de publicações, ano e quantidade de autores, qualificação da Revista no Qualis 2016, palavraschave mais citadas, instituições envolvidas, APLs e regiões mais estudadas.

$\mathrm{Na}$ Tabela 1, encontra-se o número de quantidades de autores por artigo e foram identificados mais artigos com até dois autores (45,7\%), APL e Capital Social (seis artigos) e APL e Governança Local (dez artigos). Pode-se observar também que APL e Capital Social teve seis artigos com quatro autores. 
Os artigos relacionados a três e quatro autores também se apresentaram relevantes, demonstrando de modo geral o envolvimento de vários pesquisadores, que podem representar pesquisas multidisciplinares e o envolvimento de várias instituições; no entanto, em termos de definição precisa sobre a contribuição de cada pesquisador, seria necessário um estudo aprofundado para o levantamento sobre a relevância dos autores secundários.

Tabela 1 - Eixos de análise e quantidade de autores por artigo*

\begin{tabular}{|c|c|c|c|c|}
\hline \multirow{2}{*}{\multicolumn{2}{|c|}{ Quantidade de autores por artigo }} & \multicolumn{2}{|c|}{ Eixo de análise } & \multirow{3}{*}{$\begin{array}{c}\text { TOTAL } \\
1 \\
2,9 \%\end{array}$} \\
\hline & & APL e Capital Social & APL e Governança & \\
\hline 1 Autor & $\begin{array}{l}\text { Contagem } \\
\% \text { do Total }\end{array}$ & $\begin{array}{c}0 \\
0,0 \%\end{array}$ & $\begin{array}{c}1 \\
2,9 \%\end{array}$ & \\
\hline 2 Autores & $\begin{array}{l}\text { Contagem } \\
\% \text { do Total }\end{array}$ & $\begin{array}{c}6 \\
17,1 \%\end{array}$ & $\begin{array}{c}10 \\
28,6 \%\end{array}$ & $\begin{array}{c}16 \\
45,7 \%\end{array}$ \\
\hline 3 Autores & $\begin{array}{l}\text { Contagem } \\
\% \text { do Total }\end{array}$ & $\begin{array}{c}3 \\
8,6 \%\end{array}$ & $\begin{array}{c}5 \\
14,3 \%\end{array}$ & $\begin{array}{c}8 \\
22,9 \%\end{array}$ \\
\hline 4 Autores & $\begin{array}{l}\text { Contagem } \\
\% \text { do Total }\end{array}$ & $\begin{array}{c}6 \\
17,1 \%\end{array}$ & $\begin{array}{c}3 \\
8,6 \%\end{array}$ & $\begin{array}{c}9 \\
25,7 \%\end{array}$ \\
\hline 6 Autores & $\begin{array}{l}\text { Contagem } \\
\% \text { do Total }\end{array}$ & $\begin{array}{c}0 \\
0,0 \%\end{array}$ & $\begin{array}{c}1 \\
2,9 \%\end{array}$ & $\begin{array}{c}1 \\
2,9 \%\end{array}$ \\
\hline TOTAL & $\begin{array}{l}\text { Contagem } \\
\% \text { do Total }\end{array}$ & $\begin{array}{c}15 \\
42,9 \%\end{array}$ & $\begin{array}{c}20 \\
57,1 \%\end{array}$ & $\begin{array}{c}35 \\
100,0 \%\end{array}$ \\
\hline
\end{tabular}

* Dados da pesquisa.

Fonte: Elaborada pelos autores (2019).

De acordo com o horizonte temporal identificado (2004 a 2018), o Gráfico 1 apresenta a distribuição dos artigos ao longo desse período. Constatou-se que os anos de 2013 e 2017 foram os de maior número de publicações. Considerando os eixos de estudo, identificou-se que o eixo APL e Governança destacou-se na maioria dos anos, demonstrando que modelos organizacionais com base na associação, cooperação e articulação ganham cada vez mais destaque na literatura. A grande presença de pesquisas relacionadas a esta área pode se justificar pela maior conscientização da sociedade frente a definições e à escolha de políticas públicas, principalmente em esferas locais relacionadas a diversos setores da sociedade. 


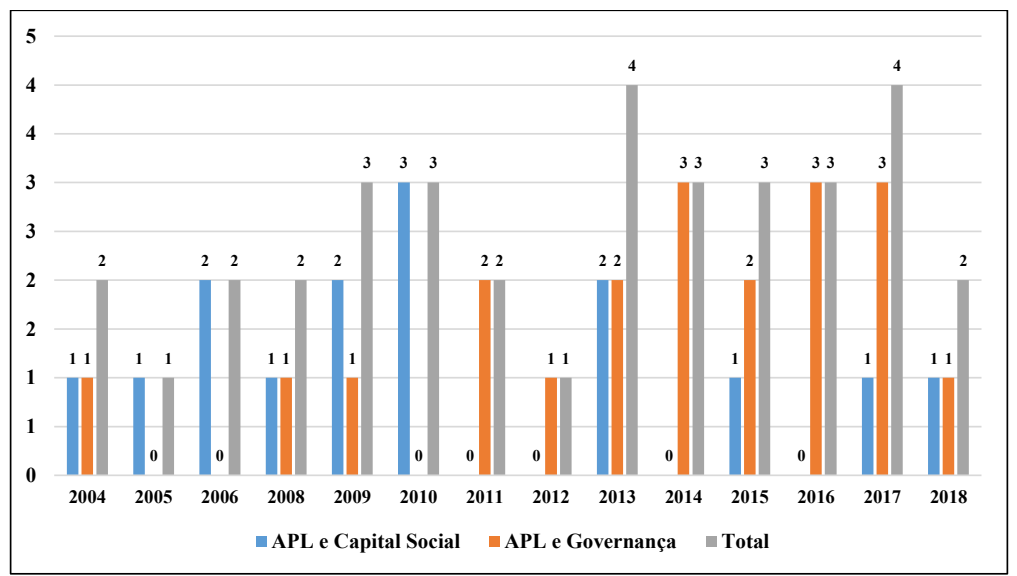

Gráfico 1 - Ano e quantidade de artigos publicados*

* Dados da pesquisa.

Fonte: Elaborada pelos autores (2019).

$\mathrm{Na}$ Tabela 2, foi elaborado um ranking dos periódicos com maior número de publicações. A revista Gestão \& Produção - SP teve o maior número de publicações (quatro); e, conforme as análises, três artigos tratam de APL e Capital Social e um artigo trata de APL e Governança Local. A revista Organizações em Contexto - SP, segunda no ranking, contou com um artigo de APL e Capital Social e dois artigos tratando de APL e Governança Local. Mas, de modo geral, nenhum periódico se destacou em função do número reduzido de artigos.

Tabela 2 - Periódicos*

\begin{tabular}{lcc}
\hline \multicolumn{1}{c}{ Revistas } & N & \% \\
\hline Gestão \& Produção - SP & 4 & $11,4 \%$ \\
Organizações em contexto - SP & 3 & $8,6 \%$ \\
Desenvolvimento em Questão - RS & 2 & $5,7 \%$ \\
IBEPES - PR & 2 & $5,7 \%$ \\
Organização e Sociedade (O\&S) - BA & 2 & $5,7 \%$ \\
Revista de Administração Pública - RJ & 2 & $5,7 \%$ \\
RESR - SP & 2 & $5,7 \%$ \\
Revista da Micro e Pequena Empresa - SP & 2 & $5,7 \%$ \\
Revista de Ciências da Administração & 2 & $5,7 \%$ \\
Administração em Diálogo - SP & 1 & $2,9 \%$ \\
Ambiente \& Sociedade - SP & 1 & $2,9 \%$ \\
Interações - MS & 1 & $2,9 \%$ \\
Interciência - CHILE & 1 & $2,9 \%$ \\
RAP - RJ & 1 & $2,9 \%$ \\
REAd - RS & 1 & $2,9 \%$ \\
REGE - SP & 1 & $2,9 \%$
\end{tabular}




\begin{tabular}{lcc} 
Revista Brasileira de Gestão Urbana - PR & 1 & $2,9 \%$ \\
Revista Brasileira de Inovação - RJ & 1 & $2,9 \%$ \\
A Economia em Revista - UEM & 1 & $2,9 \%$ \\
Ciência da Informação - DF & 1 & $2,9 \%$ \\
Economia e Gestão - MG & 1 & $2,9 \%$ \\
RER - RJ & 1 & $2,9 \%$ \\
Revista de Administração - RAUSP - SP & 1 & $2,9 \%$ \\
\hline TOTAL & $\mathbf{3 5}$ & $\mathbf{1 0 0 \%}$ \\
\hline
\end{tabular}

* Dados da pesquisa.

Fonte: Elaborada pelos autores (2019).

Quanto a revistas pelo Qualis (2016), conforme a Tabela 3, verificou-se que as publicações no Qualis A2 estão totalmente relacionadas ao eixo de estudo APL e Governança Local. Em relação à incidência de artigos publicados, constatou-se a concentração nos Qualis B1 e B2. Dessa maneira, conclui-se que as produções relacionadas aos eixos estudados atendem aos aspectos técnico-científicos dos periódicos com classificações mais elevadas, demonstrando qualidade e relevância na área.

Tabela 3 - Avaliação das revistas (Qualis 2016) *

\begin{tabular}{|c|c|c|c|c|c|c|}
\hline \multirow[b]{2}{*}{ Avaliação das revistas } & \multicolumn{4}{|c|}{ Tema } & \multirow[b]{2}{*}{ TOTAL } & \multirow[b]{2}{*}{$\%$} \\
\hline & $\begin{array}{c}\text { APL e Capital } \\
\text { Social }\end{array}$ & $\%$ & $\begin{array}{c}\text { APL e } \\
\text { Governança }\end{array}$ & $\%$ & & \\
\hline Qualis A2 & 0 & $0 \%$ & 3 & $15 \%$ & 3 & $9 \%$ \\
\hline Qualis B1 & 8 & $53 \%$ & 5 & $25 \%$ & 13 & $37 \%$ \\
\hline Qualis B2 & 4 & $27 \%$ & 8 & $40 \%$ & 12 & $34 \%$ \\
\hline Qualis B3 & 2 & $13 \%$ & 1 & $5 \%$ & 3 & $9 \%$ \\
\hline Qualis B4 & 1 & $7 \%$ & 3 & $15 \%$ & 4 & $11 \%$ \\
\hline TOTAL DE ARTIGOS & 15 & $100 \%$ & 20 & $100 \%$ & 35 & $100 \%$ \\
\hline
\end{tabular}

* Dados da pesquisa.

Fonte: Elaborada pelos autores (2019).

A Tabela 4 contempla a quantidade de instituições vinculadas aos autores e envolvidas por artigo, demonstrando a maior concentração em duas Instituições de ensino; porém, com grande relevância também para a participação de somente uma instituição, o que demonstra laços fracos de intercâmbio local, regional, nacional e internacional entre instituições e pesquisadores.

Das 41 Instituições de Ensino Superior (IES) vinculadas aos artigos primeiramente em relação à sua classificação como federais, estaduais, privadas, internacionais e municipais, habitualmente tem-se - devido 
aos pilares das universidades públicas, embasados em ensino, pesquisa e extensão - que teriam a maior concentração de publicações. Realmente a maior concentração ocorreu com a predominância de instituições federais; contudo, seguida das instituições privadas e após as instituições estaduais, e, com menor relevância, apareceram instituições internacionais e municipais. As IES mais citadas são Universidade Federal de Sergipe (UFS), seguida da Universidade Estadual de Maringá (UEM), Universidade Estadual do Ceará (UECE) e Universidade Tecnológica Federal do Paraná (UTFPR).

Tabela 4 - Quantidade de instituições por artigo e classificação*

\begin{tabular}{lcc}
\hline Quantidade de instituições por artigo & $\mathbf{N}$ & $\mathbf{\%}$ \\
\hline 2 Instituições de ensino & 16 & $45,7 \%$ \\
1 Instituição de ensino & 15 & $42,9 \%$ \\
3 Instituições de ensino & 3 & $8,6 \%$ \\
4 Instituições de ensino & 1 & $2,9 \%$ \\
\hline TOTAL & $\mathbf{3 5}$ & $\mathbf{1 0 0 \%}$ \\
\hline Características das instituições & $\mathrm{N}$ & $\%$ \\
Instituições Federais & 16 & $39,0 \%$ \\
Instituições Privadas & 12 & $29,3 \%$ \\
Instituições Estaduais & 10 & $24,4 \%$ \\
Instituições Internacionais & 2 & $4,9 \%$ \\
Instituições Municipais & 1 & $2,4 \%$ \\
\hline TOTAL & $\mathbf{4 1}$ & $\mathbf{1 0 0} \%$ \\
\hline
\end{tabular}

* Dados da pesquisa.

Fonte: Elaborada pelos autores (2019).

Conforme a Tabela 5, dos 35 artigos levantados: dois foram revisões de literaturas; um estudo de caso refere-se uma região da Alemanha; os 32 restantes foram estudos de caso de regiões brasileiras. Um ponto que pode ser destacado neste âmbito é que ainda são recentes e poucas as publicações que trazem somente discussões teóricas sobre esse tema. Predominaram estudos concentrados na Região Sul, seguidos pelas Regiões Nordeste e Sudeste, e em menor concentração de estudos apresentou-se a Região Norte. Não foram identificados estudos relacionados à Região CentroOeste, e destacaram-se os Estados do Paraná na Região Sul, o Ceará na Região Nordeste e São Paulo na Região Sudeste.

Essa informação corrobora com o estudo de Ouro e Barreto (2014), os quais identificaram que, em relação aos APLs mais estudados, a maioria destes se encontra no Sudeste ou Sul, com exceção do APL do agreste pernambucano, demonstrando, assim, a escassez de estudos 
no Norte e Nordeste e a falta de estudos no Centro-Oeste. Estudos nas regiões onde houve poucas pesquisas em relação ao APL seriam de grande importância para o avanço do campo, pois mostrariam outras realidades do APL no Brasil.

Tabela 5 - Regiões estudadas*

\begin{tabular}{lcc}
\hline Regiões estudadas & N & \% \\
\hline Região Sul & 12 & $37,5 \%$ \\
Região Nordeste & 9 & $28,1 \%$ \\
Região Sudeste & 9 & $28,1 \%$ \\
Região Norte & 2 & $6,3 \%$ \\
\hline TOTAL & $\mathbf{3 2}$ & $\mathbf{1 0 0 \%}$ \\
\hline PR - Região Sul & 9 & $25,7 \%$ \\
CE - Região Nordeste & 5 & $14,3 \%$ \\
SP - Região Sudeste & 5 & $14,3 \%$ \\
MG - Região Sudeste & 3 & $8,6 \%$ \\
SE - Região Nordeste & 3 & $8,6 \%$ \\
RO - Região Norte & 2 & $5,7 \%$ \\
RS - Região Sul & 2 & $5,7 \%$ \\
Revisão de literatura & 2 & $5,7 \%$ \\
RJ - Região Sudeste & 1 & $2,9 \%$ \\
SC - Região Sul & 1 & $2,9 \%$ \\
BA - Região Nordeste & 1 & $2,9 \%$ \\
Alemanha & 1 & $2,9 \%$ \\
\hline TOTAL & 35 & $\mathbf{1 0 0 \%}$ \\
\hline
\end{tabular}

* Dados da pesquisa.

Fonte: Elaborada pelos autores (2019).

A Tabela 6 apresenta os tipos de APLs estudados nos artigos. Em primeiro lugar, tanto para APL e Capital Social, quanto para APL e Governança Local, os APLs mais estudados foram de Têxtil e Confecções, seguidos pelos APLs de software e tecnologia, mas que se encontram apenas nos artigos de APLs e Governança Local.

Cabe destacar o Estado do Paraná como objeto dos estudos mais frequentes, onde dos 11 artigos relacionados ao APL Têxtil e Confecções, seis foram efetuados no Estado, bem como dos cinco relacionados ao APL de Software e Tecnologia, quatro se relacionam ao PR, provavelmente fruto das características industriais e tecnológicas em que se encontra o Estado e pela presença de inúmeras instituições de ensino em seu território, sejam estas públicas ou privadas. 
Tabela 6 - Tipos de APL estudadas*

\begin{tabular}{|c|c|c|c|c|c|}
\hline \multirow[b]{2}{*}{ APL } & \multicolumn{4}{|c|}{ Tema } & \multirow[b]{2}{*}{ TOTAL } \\
\hline & $\begin{array}{c}\text { APL e Capital } \\
\text { Social }\end{array}$ & $\%$ & $\begin{array}{c}\text { APL e } \\
\text { Governança }\end{array}$ & $\%$ & \\
\hline APL Têxtil e Confecções & 4 & $27 \%$ & 7 & $35 \%$ & 11 \\
\hline APL de Software e Ttecnologia & 0 & $0 \%$ & 5 & $25 \%$ & 5 \\
\hline APL da Madeira e Moveleira & 1 & $7 \%$ & 3 & $15 \%$ & 4 \\
\hline APL da Cerâmica & 0 & $0 \%$ & 2 & $10 \%$ & 2 \\
\hline APL de Calçados & 0 & $0 \%$ & 2 & $10 \%$ & 2 \\
\hline Análise de Redes & 2 & $13 \%$ & 0 & $0 \%$ & 2 \\
\hline Clusters de PMEs & 2 & $13 \%$ & 0 & $0 \%$ & 2 \\
\hline APL de Agros Silvicultores & 0 & $0 \%$ & 1 & $5 \%$ & 1 \\
\hline APL de Alimentos e Agroempresas & 0 & $0 \%$ & 1 & $5 \%$ & 1 \\
\hline APL do Agronegócio & 0 & $0 \%$ & 1 & $5 \%$ & 1 \\
\hline APL do Álcool & 0 & $0 \%$ & 1 & $5 \%$ & 1 \\
\hline APL do Café & 0 & $0 \%$ & 1 & $5 \%$ & 1 \\
\hline APL do Camarão & 0 & $0 \%$ & 1 & $5 \%$ & 1 \\
\hline APL do Leite & 0 & $0 \%$ & 1 & $5 \%$ & 1 \\
\hline APL Agricultura Irrigada & 1 & $7 \%$ & 0 & $0 \%$ & 1 \\
\hline APL de vinícolas & 1 & $7 \%$ & 0 & $0 \%$ & 1 \\
\hline APL do Sisal & 1 & $7 \%$ & 0 & $0 \%$ & 1 \\
\hline Associação Comunitária & 1 & $7 \%$ & 0 & $0 \%$ & 1 \\
\hline Cooperativas Segmento Lácteo & 1 & $7 \%$ & 0 & $0 \%$ & 1 \\
\hline Trade Turístico & 1 & $7 \%$ & 0 & $0 \%$ & 1 \\
\hline TOTAL DE ARTIGOS & 15 & & 20 & & 35 \\
\hline
\end{tabular}

* Dados da pesquisa.

Fonte: Elaborada pelos autores (2019).

Foi identificado o uso de 53 palavras-chave nos artigos analisados, conforme a Tabela 7, em ordem de representatividade (maior frequência), e a palavra-chave Arranjos Produtivos Locais aparece em 25 artigos, (71\%) em relação aos 35 artigos. Excluindo as palavras-chave utilizadas na pesquisa "Arranjos Produtivos Locais, Capital Social e Governança” a palavra "Cooperação" foi a palavra com maior incidência, em seis artigos, seguido de "Desenvolvimento Local"e "Micro, pequenas e médias empresas" constantes em quatro artigos.

A palavra "Cooperação", a qual não surpreende, foi uma das mais citadas, já que cooperação é um fator de destaque em um APL; através dela que se torna possível o funcionamento do APL e o desenvolvimento (DINIZ; LEMOS, 2005), consequentemente o ganho de vantagens competitivas para a empresas (micro, pequenas e médias empresas) têm um relevante papel econômico na geração de emprego e renda; então, os 
estudos voltados a esse tipo de empresa se justificam, e "Desenvolvimento Local" é uma palavra-chave para APLs, pois esse tipo de aglomerado é um mecanismo eficaz de produção do desenvolvimento local.

Tabela 7 - Palavras-chave*

\begin{tabular}{|c|c|c|c|c|c|}
\hline \multirow[b]{2}{*}{ Palavras chave } & \multicolumn{4}{|c|}{ Tema } & \multirow[b]{2}{*}{ TOTAL } \\
\hline & $\begin{array}{c}\text { APLe } \\
\text { Capital Social }\end{array}$ & $\%$ & $\begin{array}{c}\text { APL e } \\
\text { Governança }\end{array}$ & $\%$ & \\
\hline Arranjos Produtivos Locais & 11 & $73 \%$ & 14 & $70 \%$ & 25 \\
\hline Governança & 0 & $0 \%$ & 8 & $40 \%$ & 8 \\
\hline Cooperação & 0 & $0 \%$ & 6 & $30 \%$ & 6 \\
\hline Capital Social & 6 & $40 \%$ & 0 & $0 \%$ & 6 \\
\hline Sem Palavras-chave & 1 & $7 \%$ & 4 & $20 \%$ & 5 \\
\hline Desenvolvimento Local & 3 & $20 \%$ & 1 & $5 \%$ & 4 \\
\hline Micro, Pequenas e Médias Empresas & 4 & $27 \%$ & 0 & $0 \%$ & 4 \\
\hline Redes Sociais & 3 & $20 \%$ & 0 & $0 \%$ & 3 \\
\hline Clusters & 1 & $7 \%$ & 1 & $5 \%$ & 2 \\
\hline Competição & 0 & $0 \%$ & 2 & $10 \%$ & 2 \\
\hline Contexto Institucional & 0 & $0 \%$ & 2 & $10 \%$ & 2 \\
\hline Desenvolvimento Regional & 1 & $7 \%$ & 1 & $5 \%$ & 2 \\
\hline Estrutura de Governança & 0 & $0 \%$ & 2 & $10 \%$ & 2 \\
\hline Políticas Públicas & 0 & $0 \%$ & 2 & $10 \%$ & 2 \\
\hline Cooperação & 2 & $13 \%$ & 0 & $0 \%$ & 2 \\
\hline Melhoria Contínua & 2 & $13 \%$ & 0 & $0 \%$ & 2 \\
\hline Ações Coletivas & 0 & $0 \%$ & 1 & $5 \%$ & 1 \\
\hline Aglomeração Produtiva & 0 & $0 \%$ & 1 & $5 \%$ & 1 \\
\hline Agronegócio & 0 & $0 \%$ & 1 & $5 \%$ & 1 \\
\hline Aumento do Desempenho & 0 & $0 \%$ & 1 & $5 \%$ & 1 \\
\hline Cadeias Globais de Produção & 0 & $0 \%$ & 1 & $5 \%$ & 1 \\
\hline Competitividade & 0 & $0 \%$ & 1 & $5 \%$ & 1 \\
\hline Comunidades de Aprendizagem & 0 & $0 \%$ & 1 & $5 \%$ & 1 \\
\hline Desempenho Organizacional & 0 & $0 \%$ & 1 & $5 \%$ & 1 \\
\hline Fatores da Governança & 0 & $0 \%$ & 1 & $5 \%$ & 1 \\
\hline Formas de Governança & 0 & $0 \%$ & 1 & $5 \%$ & 1 \\
\hline Ganhos Coletivos & 0 & $0 \%$ & 1 & $5 \%$ & 1 \\
\hline Núcleo Empresarial & 0 & $0 \%$ & 1 & $5 \%$ & 1 \\
\hline Planejamento Urbano e Regional & 0 & $0 \%$ & 1 & $5 \%$ & 1 \\
\hline Sistemas Produtivos Locais & 0 & $0 \%$ & 1 & $5 \%$ & 1 \\
\hline Stakeholders & 0 & $0 \%$ & 1 & $5 \%$ & 1 \\
\hline Tecnologia da Informação & 0 & $0 \%$ & 1 & $5 \%$ & 1 \\
\hline Territórios & 0 & $0 \%$ & 1 & $5 \%$ & 1 \\
\hline Ações Conjuntas & 1 & $7 \%$ & 0 & $0 \%$ & 1 \\
\hline Análise de Redes Sociais & 1 & $7 \%$ & 0 & $0 \%$ & 1 \\
\hline
\end{tabular}




\begin{tabular}{|c|c|c|c|c|c|}
\hline \multirow[b]{2}{*}{ Palavras chave } & \multicolumn{4}{|c|}{ Tema } & \multirow[b]{2}{*}{ TOTAL } \\
\hline & $\begin{array}{c}\text { APLe } \\
\text { Capital Social }\end{array}$ & $\%$ & $\begin{array}{c}\text { APL e } \\
\text { Governança }\end{array}$ & $\%$ & \\
\hline Baixa Renda & 1 & $7 \%$ & 0 & $0 \%$ & 1 \\
\hline Conhecimento & 1 & $7 \%$ & 0 & $0 \%$ & 1 \\
\hline Cooperativa de Crédito & 1 & $7 \%$ & 0 & $0 \%$ & 1 \\
\hline Desempenho & 1 & $7 \%$ & 0 & $0 \%$ & 1 \\
\hline Desenvolvimento Comunitário & 1 & $7 \%$ & 0 & $0 \%$ & 1 \\
\hline Estratégias & 1 & $7 \%$ & 0 & $0 \%$ & 1 \\
\hline Fatores Inibidores & 1 & $7 \%$ & 0 & $0 \%$ & 1 \\
\hline Gestão da Qualidade & 1 & $7 \%$ & 0 & $0 \%$ & 1 \\
\hline Informação & 1 & $7 \%$ & 0 & $0 \%$ & 1 \\
\hline Inovação & 1 & $7 \%$ & 0 & $0 \%$ & 1 \\
\hline Interação & 1 & $7 \%$ & 0 & $0 \%$ & 1 \\
\hline Poder Simbólico & 1 & $7 \%$ & 0 & $0 \%$ & 1 \\
\hline Proximidade & 1 & $7 \%$ & 0 & $0 \%$ & 1 \\
\hline Redes de Competência & 1 & $7 \%$ & 0 & $0 \%$ & 1 \\
\hline Redes de Cooperação & 1 & $7 \%$ & 0 & $0 \%$ & 1 \\
\hline Redes de Cooperativas & 1 & $7 \%$ & 0 & $0 \%$ & 1 \\
\hline Sistema de Medição de Desempenho & 1 & $7 \%$ & 0 & $0 \%$ & 1 \\
\hline Sistemas Locais de Inovação & 1 & $7 \%$ & 0 & $0 \%$ & 1 \\
\hline TOTAL DE ARTIGOS & 15 & & 20 & & 35 \\
\hline
\end{tabular}

* Dados da pesquisa.

Fonte: Elaborada pelos autores (2019).

$\mathrm{Na}$ Figura 2, foram analisados os relacionamentos entre os pesquisadores envolvendo os eixos de estudo no campo de APL (Capital Social e Governança), no período 2004-2018. Em relação à estrutura da rede de cooperação dos autores ao longo do período, identificou-se a existência da dinâmica de pequenos grupos, formados por um grande número de autores, mas que cooperam apenas entre si, sem expandir a rede com outros autores que estudam a mesma temática. Como são vários grupos de autores, o campo de estudo (APL) apresenta-se fragmentado devido a características regionais, tipos de APL, instituições de ensino, indicando que os pesquisadores têm maior facilidade de compartilhamento de ideias em redes de colaboração pequenas ou fechadas, com pouca influência nas atividades científicas uns dos outros. 
Figura 2 - Rede de autores*

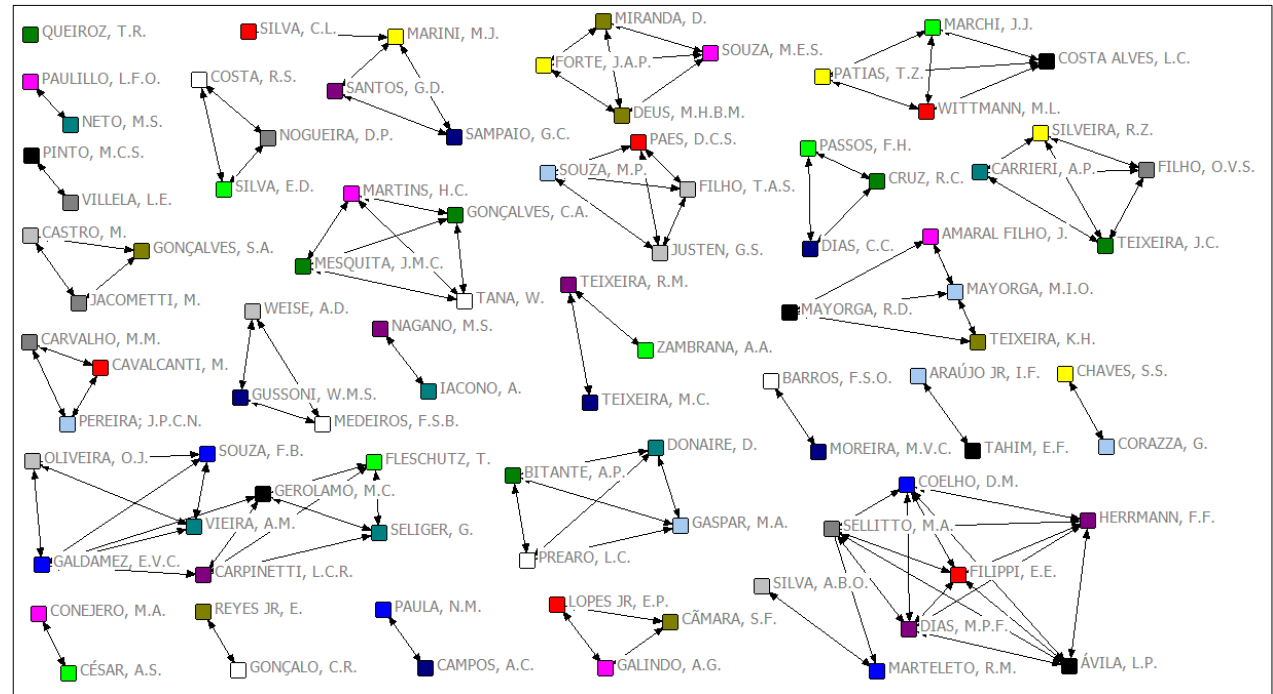

* Dados da pesquisa.

Fonte: Elaborada pelos autores (2019).

A maior rede é dos autores Miguel Afonso Sellitto, Felipe Fehlberg Herrmann, Luísa Prado Ávila, Eduardo Ernesto Filippi, Marcelo Pacheco Fernandes Dias e Daniela Miguel Coelho. Embora seja a maior rede, não é a rede mais forte, já que esses autores se relacionaram apenas entre si, na publicação de apenas um artigo.

Já os autores Edwin Vladimir Cardoza Galdámez, Luiz Cesar Ribeiro Carpinetti, Mateus Cecílio Gerolamo aparecem em dois artigos, juntamente com outros autores, significando uma maior cooperação. Aline de Aragão Zambrana e Rivanda Meira Teixeira publicaram três artigos, mas sua rede é fraca, pois não há cooperação com outros autores. Pode-se aferir também que os autores não dão continuidade nos estudos sobre esse tema, exceto pelas autoras Aline de Aragão Zambrana e Rivanda Meira Teixeira que publicaram três artigos sobre os temas.

Em relação às citações, conforme a Tabela 8 , uma publicação sobre APL e Capital Social, do ano de 2004 apresentou um extenso número de citações (324), em uma revista B1, destacando-se das demais. Pode-se inferir que seja devido ao tempo de publicação do artigo. Os dois artigos, em segundo lugar com 57 citações, foram publicados em revistas Qualis B1 e B2 com o tema de APL e Capital Social, no ano de 2009. Sobre o tema APL e Governança Local, o artigo com mais citações está publicado em uma revista com Qualis A2, com 55 citações, no ano de 2009, dos autores Lamounier Erthal Villela e Mario Couto Soares Pinto. 
Tabela 8 - Quantidade de citações*

\begin{tabular}{ccccccc}
\hline \multirow{2}{*}{ Quantidade de citações s } & \multicolumn{5}{c}{ Qualis } & TOTAL \\
\cline { 2 - 5 } & Qualis A2 & Qualis B1 & Qualis B2 & Qualis B3 & Qualis B4 & \\
\hline Nenhuma citação & 0 & 1 & 3 & 1 & 2 & 7 \\
1 citação & 0 & 2 & 0 & 0 & 1 & 3 \\
2 citações & 1 & 0 & 1 & 0 & 0 & 2 \\
3 citações & 0 & 0 & 0 & 0 & 1 & 1 \\
4 citações & 0 & 0 & 1 & 1 & 0 & 2 \\
5 citações & 0 & 2 & 0 & 0 & 0 & 2 \\
6 citações & 0 & 0 & 1 & 0 & 0 & 1 \\
7 citações & 0 & 1 & 0 & 1 & 0 & 2 \\
8 citações & 0 & 0 & 1 & 0 & 0 & 1 \\
9 citações & 0 & 2 & 1 & 0 & 0 & 3 \\
11 citações & 0 & 0 & 1 & 0 & 0 & 1 \\
12 citações & 0 & 1 & 0 & 0 & 0 & 1 \\
13 citações & 1 & 0 & 0 & 0 & 0 & 1 \\
17 citações & 0 & 0 & 1 & 0 & 0 & 1 \\
19 citações & 0 & 1 & 0 & 0 & 0 & 1 \\
22 citações & 0 & 0 & 1 & 0 & 0 & 1 \\
38 citações & 0 & 1 & 0 & 0 & 0 & 1 \\
55 citações & 1 & 0 & 0 & 0 & 0 & 1 \\
57 citações & 0 & 1 & 1 & 0 & 0 & 2 \\
342 citações & 0 & 1 & 0 & 0 & 0 & 1 \\
\hline TOTAL & $\mathbf{3}$ & $\mathbf{1 3}$ & $\mathbf{1 2}$ & $\mathbf{3}$ & $\mathbf{4}$ & $\mathbf{3 5}$ \\
\hline & & & & & & \\
\hline
\end{tabular}

* Dados da pesquisa.

Fonte: Elaborada pelos autores (2019).

Com base nos dados até aqui expostos, pode-se afirmar a representatividade da análise realizada no presente estudo, com um total de 35 artigos; assim como inferir que a vinculação entre a temática dos Arranjos Produtivos Locais em conjunto com Capital Social e Governança Local vem ampliando-se nos últimos anos.

\section{Considerações finais}

Em resposta ao objetivo do estudo que era analisar o perfil da produção científica sobre Capital Social e Governança Local no contexto dos Arranjos Produtivos Locais, identificou-se que a concentração sobre o tema "Arranjos Produtivos Locais e Capital Social" e "Arranjos Produtivos Locais e Governança Local" está nas revistas Qualis B1 e B2, em periódicos de universidades Federais, Particulares e em terceiro lugar as Estaduais, indicando que o tema aos poucos toma importância nas revistas nacionais. 
Dos 35 artigos levantados, dois foram revisões de literaturas, um estudo de caso refere-se uma região da Alemanha e os 32 restantes foram estudos de caso de regiões brasileiras. Um ponto que pode ser destacado neste âmbito é que ainda são recentes e poucas as publicações que trazem somente discussões teóricas sobre esse tema.

Predominaram estudos concentrados na Região Sul, seguidos pelas Regiões Nordeste e Sudeste. E em menor concentração de estudos apresentou-se a Região Norte. Não foram identificados estudos relacionados à Região Centro-Oeste. Em relação ao tipo de APL estudado, para APL e Capital Social, quanto para APL e Governança Local, os APLs mais estudados foram de Têxtil e Confecções, seguido pelos APLs de software e tecnologia, mas que se encontram apenas nos artigos de APLs e Governança Local.

O objetivo do estudo foi atingido e os resultados apontam, de maneira geral, que estudos na área de APLs, Capital Social e Governança Local tomam importância cada vez mais frente ao contexto atual, cuja palavra de ordem é sustentabilidade. Os resultados demonstram a necessidade de haver estudos mais aprofundados.

Destacam os autores que a cooperação e a governança contribuem para o desempenho organizacional de empresas de todos os ramos econômicos, não governamentais e cooperativas em geral. $O$ seu entendimento e experiências descritas contribuem de forma, como a cooperação e o Capital Social são forças estratégicas no crescimento e sustentabilidade. A limitação foi o uso de base nacional, o que reporta a estudo futuro com uso de base internacional para visualizar a importância do tema em outra esfera de análise.

Além disso, o estudo identificou a necessidade de futuros estudos que estabeleçam a triangulação destas três temáticas, Arranjo Produtivo Local, Capital Social e Governança Local e desenvolver instrumentos de medição de gestão. Outro ponto é aumentar a investigação acerca de como ações de cooperação afetam as três temáticas, devido ao impacto que as APLs têm na economia local e nacional com geração de empregos e diminuição da pobreza.

\section{Referências}

ARAÚJO, C. A. Bibliometria: evolução histórica e questões atuais. Em Questão, v. 12, n. 1, p. 11-32, 2006.

BEUREN, I. M. (Org.). Como elaborar trabalhos monográficos em contabilidade: teoria e prática. 3. ed. São Paulo: Atlas, 2006.

BITANTE, A. P.; DONAIRE, D.; PREARO, L. C.; GASPAR, M. A. Análise dos fatores componentes da governança em Arranjos Produtivos Locais. Organizações em contexto, São Bernardo do Campo, v. 14, n. 27, p. 235-270, jan./jun. 2018. 
BOURDIEU, Pierre. The forms of capital. In: RICHARDSON, J. (Comp.). Handbook of theory and research for the sociology of education. New York: Greenwood, 1985.

CASSIOLATO, J. E.; LASTRES, H. M. M. O foco em arranjos produtivos e inovativos locais de micro e pequenas empresas. In: CASSIOLATO, J. E.; LASTRES, H. M. M.; MACIEL, M. L. (Org.). Pequena empresa: cooperação e desenvolvimento local. Rio de Janeiro: Relume Dumará: UFRJ, Instituto de Economia, 2003. p. 21- 34.

COLEMAN, J. S. Social Capital in the Creation of Human Capital. The American Journal of Sociology - Supplement: Organizations and Institutions. Sociological and Economic Approaches to the Analysis of Social Structure, v. 94, p. S95- S120, 1988.

Foundantion of Social Theory. Cambridge, Harvard University Press, 1990. Disponível em: https://journals.sagepub.com/doi/pdf/10.1177/095169280 0012003005. Acesso em 13 fev 2019.

DINIZ, C. C; LEMOS, M. B. Economia e território. Belo Horizonte: Editora UFMG, 2005.

FERREIRA,M.T.;MEIRELES,S.S.;MACEDO,M.A.Análise do desenvolvimento de Arranjos Produtivos Locais (APL): um estudo de caso do município de Paraty (RJ). Revista de Administração Pública, v. 45, n. 2, p. 517-539, 2011.

FERREIRA, M.T. da S.; MEIRELES, S.S.; MACEDO, M.A. da S.; BARONE, F. M.; SANT'ANNA, P.R.; ZOTES, L.P. Análise do desenvolvimento de Arranjos Produtivos Locais (APLs): um estudo de caso do município de Paraty (RJ). Revista de Administração Pública (RAP) — Rio de Janeiro 45(2):517-39, mar./abr. 2011.

FLORES, A. F.; MARINI, M. J. Capital Social e Governança Local no contexto dos arranjos produtivos locais: um estudo bibliométrico. IGepec, Toledo, v. 22, n.1, p. 83-99, jan./jun. 2018.

GULATI, R. Social structure and alliance formation patterns: a longitudinal analysis. Administrative Science Quarterly, v. 40, n. 4, p. 619-652,1995.

GUSSONI, W. M. S.; WEISE, A. D.; MEDEIROS, F. S. B. Cooperação e Governança nos Arranjos Produtivos Locais: O Caso das Empresas de Software no Estado do Paraná. Editora Unijuí, ano 13, n. 29, p. 125-157, jan./mar. 2015.

LOPES, F. D.; BALDI, M. Laços sociais e formação de arranjos organizacionais cooperativos - proposição de um modelo de análise. Revista de Administração Contemporânea, Curitiba, v. 9, n. 2, p. 81-101, abr./jun. 2005.

MARINI, M. J.; SILVA, C. L.; NASCIMENTO, D. E.; STRAUHS, F. R Avaliação da contribuição de Arranjos Produtivos Locais para o desenvolvimento local. Revista Bibliográfica de Geografía y Ciencias Sociales, Barcelona, v. 17, n. 996, [s. p.], 2012.

MARTELETO, R. M; SILVA, A. B. de O. Redes e Capital Social: o enfoque da informação para o desenvolvimento local. Ci. Inf., Brasília, v. 33, n. 3, p. 41-49, set./ dez. 2004. 
NORONHA, E. G.; TURCHI, L. Política Industrial e ambiente institucional na análise de arranjo produtivo local. Brasil: Ipea, 2005. Disponível em: www. ipea.gov/publicações/textoparadiscussão. Acesso em: 31 jan. 2019.

OURO, A.; BARRETO, I. Um Estudo Bibliométrico Sobre Arranjo Produtivo Local. Cadernos de Gestão e empreendedorismo, v. 2, n. 1, p. 32-50, jan./abr. 2014.

PASSADOR, C. S. O projeto escola do campo (1990-2002) do estado do Paraná: Capital Social, redes e agricultura familiar nas políticas públicas. Orientador: Pedro Jacobi. 2003. 164 p. Tese (Doutorado em Educação) - Pós-Graduação em Educação, Universidade de São Paulo, São Paulo, Brasil, 2003.

PORTER, M. E. The competitive advantage of nations. New York: Basic Books, 1990

PORTER, Michael E. Clusters and the new economics of competition. Harvard Business Review, v. 76, n. 6, p. 77-90, nov/dec. 1998.

PUTNAM, R. Comunidade e Democracia. Rio de Janeiro: FGV, 2000.

SANTOS,A.M.S.P.Economia,espaçoesociedadenoRiodeJaneiro.RiodeJaneiro: Editora FGV, 2003.

SANTOS, M. H. de C. Governabilidade, governança e democracia: criação da capacidade governativa e relações executivo-legislativo no Brasil pós-constituinte. Dados - Revista de Ciências Sociais, Rio de Janeiro, v. 40, n. 3, p. 335-376, 1997.

SCHMITZ, H.; KNORRINGA, P. Learning from global buyers. Journal of Development Studies, v. 37, n. 2, p. 177-205, 2000.

SOUZA, A. R.; BRITO, M. J.; SILVA, P.J.; ARAÚJO, U. P. Cooperação no APL de Santa Rita do Sapucaí. RAM - Rev. Adm. Mackenzie, São Paulo, v. 16, n. 1, p. 157-187, jan./fev. 2015.

STORPER, M.; HARRISON, B. Flexibility, hierarchy and regional development: the chan ging structure industrial production systems and their forms of governance in the 1990s. Research Policy, v. 20,. Amsterdam, The Netherlands, issue 5, p 407-422, 1991.

SUZIGAN, W (Org.). Identificação, mapeamento e caracterização estrutural de arranjos produtivos locais no Brasil. Relatório Consolidado. Rio de Janeiro: IPEA-DISET, out. 2006.

SUZIGAN, W. et al:; GARCIA, R.; FURTADO, J. Governança de sistemas de MPME em clusters industriais. Rio de Janeiro: UFRJ, 2002. Disponível em: http:// www.ie.ufrj.br/redesist/ NTF2/NT\%20Suzigan.PDF. Acesso em: 25 mar. 2019.

VERSCHOORE, J.; BALESTRIN, A. Redes de cooperação empresarial: estratégias de gestão na nova economia. Porto Alegre: Bookman, 2008.

VILPOUX, O. F.; OLIVEIRA, E. J. de. Instituições informais e governanças em Arranjos Produtivos Locais. R. Econ. contemp., Rio de Janeiro, v. 14, n. 1, p. 85111, jan./abr. 2010. Disponível em: http://www.scielo.br/scielo.php?pid=S141598482010000100005\&script=sci_abstract\&tlng=pt. Acesso em: 15 mar. 2019.

WEGNER,D.;PADULA,A.D.Estratégias de crescimento e a governança de redes horizontais de empresas: o caso da maior rede cooperativa de varejo de alimentos 
na Alemanha. In: ENCONTRO DE ESTUDOS ORGANIZACIONAIS DA ANPAD, 7., 2010, Florianópolis. Anais... Rio de Janeiro: Anpad, 2010.

ZACCARELLI, S. B.; TELLES, R.; SIQUEIRA, J. P. L.; BOAVENTURA, J. M. G.; DONAIRE, D. Clusters e redes de negócios: Uma nova visão para gestão dos negócios. São Paulo: Atlas, 2008.

Submetido: $24 / 04 / 2019$

Aceito: 28/08/2019 


\title{
BIBLIOMETRIC ANALYSIS ON SOCIAL CAPITAL AND LOCAL GOVERNANCE IN THE CONTEXT OF LOCAL PRODUCTIVE ARRANGEMENTS
}

\begin{abstract}
The study analyzed the scientific production on Social Capital and Local Governance in the context of Local Productive Arrangements. The research was exploratory and bibliometric (documentary), of quantitative nature, because the data came from only secondary sources. The survey of the publications was carried out at the CAPES Journal Portal (Coordination for the Improvement of Higher Education Personnel), SPELL (Scientific Periodicals Electronic Library) and SCIELO (Scientific Electronic Library Online). The results show that 2013 and 2017 were the years with the largest number of publications, with the largest number of articles concentrated in journals B1 and B2. The most studied APLs were in the textile and clothing sector, followed by software and technology, with more concentrated studies in the South, Southeast and Northeast, few studies in the North and no studies in the Midwest. And that research on Social Capital in its various biases needs to be expanded.
\end{abstract}

Keywords: Local productive arrangements. Social capital. Governance. Bibliometrics.

\section{ANÁLISIS BIBLIOMÉTRICO SOBRE CAPITAL SOCIAL Y GOBIERNO LOCAL EN EL CONTEXTO DE LOS ARRANJOS PRODUCTIVOS LOCALES}

\begin{abstract}
Resumen
El estudio analizó la producción científica sobre Capital Social y gobernanza local en el contexto de los arreglos productivos locales. La investigación fue exploratoria y bibliométrica (documental), de naturaleza cuantitativa, porque los datos provenían solo de fuentes secundarias. La encuesta de las publicaciones se realizó en el Portal de la revista CAPES (Coordinación para la mejora del personal de educación superior), SPELL (Biblioteca electrónica de publicaciones periódicas científicas) y SCIELO (Biblioteca electrónica en línea científica). Los resultados muestran que 2013 y 2017 fueron los años con el mayor número de publicaciones, con el mayor número de artículos concentrados en las revistas B1 y B2. Las APL más estudiadas fueron en el sector textil y de la confección, seguidas de software y tecnología, con estudios más concentrados en el sur, sudeste y noreste, pocos estudios en el norte y ningún estudio en el medio oeste. Y esa investigación sobre el Capital Social en sus diversos prejuicios debe ampliarse.
\end{abstract}

Palabras clave: Arreglos productivos locales. Capital Social. Gobernanza. Bibliometría. 